\title{
Dislocation after total hip arthroplasty with 28 and 32-mm femoral head
}

\author{
Einar Amlie • Øystein Høvik • Olav Reikerås
}

Received: 23 March 2010/Accepted: 12 May 2010/Published online: 27 May 2010

(C) The Author(s) 2010. This article is published with open access at Springerlink.com

\begin{abstract}
Background Dislocation after primary total hip arthroplasty (THA) is a significant complication that occurs in $2-5 \%$ of patients. It has been postulated that increasing the femoral head diameter may reduce the risk of dislocation. The purpose of this paper is to report our experiences with a change from a 28 to a $32-\mathrm{mm}$ femoral head.

Materials and methods The retrospective cohort study includes 2572 primary THA performed with a 28 or $32 \mathrm{~mm}$ diameter femoral head in the period February 2002 to July 2009. All patients were operated with a posterolateral approach, and all except 18 were operated because of osteoarthritis. Cemented stems were used in 1991 cases and uncemented stems in 581 cases. Cemented cups were used in 2,230 cases and uncemented cups in 342 cases. The patients have been routinely followed for $1-8$ years in the 28-mm femoral head group and from $0.5-7.5$ years in the 32 femoral head group. We defined a dislocation as an event in which the hip required reduction by a physician. Results Dislocation occurred in 49 hips with a $28-\mathrm{mm}$ femoral head and in 4 hips with a 32-mm femoral head with an odds ratio of $6.06(95 \% \mathrm{CI}=2.05-17.8)$ $(P<0.001)$. Otherwise, there were no significant associations between sex, age, diagnosis and type of prosthesis.

Conclusions Multivariate analyses of patients operated at our hospital indicate a significant association between
\end{abstract}

\footnotetext{
E. Amlie $\cdot \varnothing$. Høvik

Department of Orthopaedic Surgery,

Lovisenberg Deaconal Hospital, Oslo, Norway

O. Reikerås $(\square)$

Faculty Division Rikshospitalet, Rikshospitalet,

University of Oslo, 0027 Oslo, Norway

e-mail: olav.reikeras@ rikshospitalet.no
}

femoral head diameter and dislocation after THA. There were no significant associations between dislocation and sex, age, diagnosis, or type of prosthesis.

Keywords Dislocation · Head size - Hip arthroplasty · Prosthesis

\section{Introduction}

Dislocation of a primary total hip arthroplasty (THA) is a significant complication. In 1982 Woo and Morrey reviewed 10,500 primary THAs and identified an overall dislocation rate of $3.2 \%$ [1]. Later studies have reported a rate of $2-5 \%[2,3]$. Some hips dislocate more than once, and patients with recurrent dislocation have reported a worse outcome than after uncomplicated THA [4, 5].

The risk factors that predispose to dislocation include patient-related, operative, and implant design variables [6]. It has been postulated that an increased femoral head diameter may reduce the risk of dislocation as a result of reduced component-component or component-bone impingement and increased translation that is required for hip dislocation [7-9]. Despite these theoretical advantages, the use of larger femoral heads in THA has been limited as a result of concerns regarding increased production of polyethylene wear debris and osteolysis. This is based primarily on the study of Livermore et al. [10] in which wear of 385 cemented total hips with conventional polyethylene liners articulating with 22,28 , and 32-mm femoral heads was measured. They reported increased volumetric wear rates, total volumetric wear, and amount of osteolysis for 32-mm heads compared with 22 and 28 -mm heads.

Highly cross-linked polyethylene (XLPE) is an alternative bearing surface that was developed to improve 
polyethylene wear resistance and reduce osteolysis. XLPE has been studied extensively in vitro $[11,12]$, and in a Boston hip simulator it was shown that the linear wear rate of electron beam XLPE was extremely low and independent of femoral head size for standard size femoral heads $(22-32 \mathrm{~mm})$ [13]. Preliminary clinical studies of XLPE in small series of patients undergoing THA have confirmed these promising findings with a $45-99 \%$ reduction in wear compared with conventional polyethylene at 3-5 years [14-20]. Based on these results we have increased the size of the femoral head gradually from 28 to $32 \mathrm{~mm}$ in an effort to reduce the incidence of dislocation after THA. The purpose of this paper is to report our experiences with this change to a larger femoral head.

\section{Materials and methods}

The study was performed in accordance with the ethical standards of the 1964 Declaration of Helsinki as revised in 2000, and all patients gave informed consent. The study cohort includes all 2,572 primary THA performed with a 28 or $32 \mathrm{~mm}$ diameter femoral head in 2,257 patients (1,673 females and 584 men) at our clinic from February 2002 to July 2009 (Fig. 1). With the introduction of highly cross-linked polyethylene we gradually increased use of the $32-\mathrm{mm}$ femoral head, and 88 patients had bilateral operations with different head size.

The mean age at the time of the operation was 68 years (range, 24-93 years) in the cohort with a $28 \mathrm{~mm}$ diameter femoral head, and 69 years (range, 24-91 years) in the cohort with a $32 \mathrm{~mm}$ diameter femoral head. There were 1,047 women (1,182 hips) and 365 men (395 hips) in the $28 \mathrm{~mm}$ cohort and 691 women (739 hips) and $242 \mathrm{men}$
(256 hips) in the $32 \mathrm{~mm}$ cohort. All patients were operated with a posterolateral approach, and all except 18 were operated for osteoarthritis of the hip, either primary $(2,296$ cases) or secondary (258 cases). They were operated with a cemented stem in 1991 cases and an uncemented stem in 581 cases, and with a cemented cup in 2,230 cases and an uncemented cup in 342 cases.

The patients have been routinely followed for 1-8 years in the $28 \mathrm{~mm}$ group and for $0.5-7.5$ years in the $32 \mathrm{~mm}$ group, and we defined dislocation as an event in which the hip required reduction by a physician. During follow-up, five hips have been revised because of infection and eight because of mechanical failures. Altogether 126 patients have died of unrelated causes. These patients have been censored at time point of revision or death. Survival free of dislocation after arthroplasty was estimated by use of the Kaplan-Meier survival method. The Cox proportional hazards model was used in a multiple variable model to assess the risk of dislocation in association with femoral head diameter, with adjustment for sex, age, diagnosis, and type of prosthesis (SPSS, Chicago, IL, USA). An alpha level of 0.05 was set for significance.

\section{Results}

Dislocation occurred in 49 hips $(3.1 \%)$ with a $28-\mathrm{mm}$ femoral head and in four hips $(0.4 \%)$ with a $32-\mathrm{mm}$ femoral head $(P<0.001)$. The Kaplan-Meier survival from dislocation is presented in Table 1 and in Fig. 2. Multivariate analysis shows an odds ratio of 6.06 (95\% $\mathrm{CI}=2.05-17.8)$ for the 28-mm femoral head compared with the $32-\mathrm{mm}$ femoral head $(P<0.001)$. In the whole cohort, there were no significant associations with sex
Fig. 1 Use of 28 and 32-mm femoral heads during 2002-2009

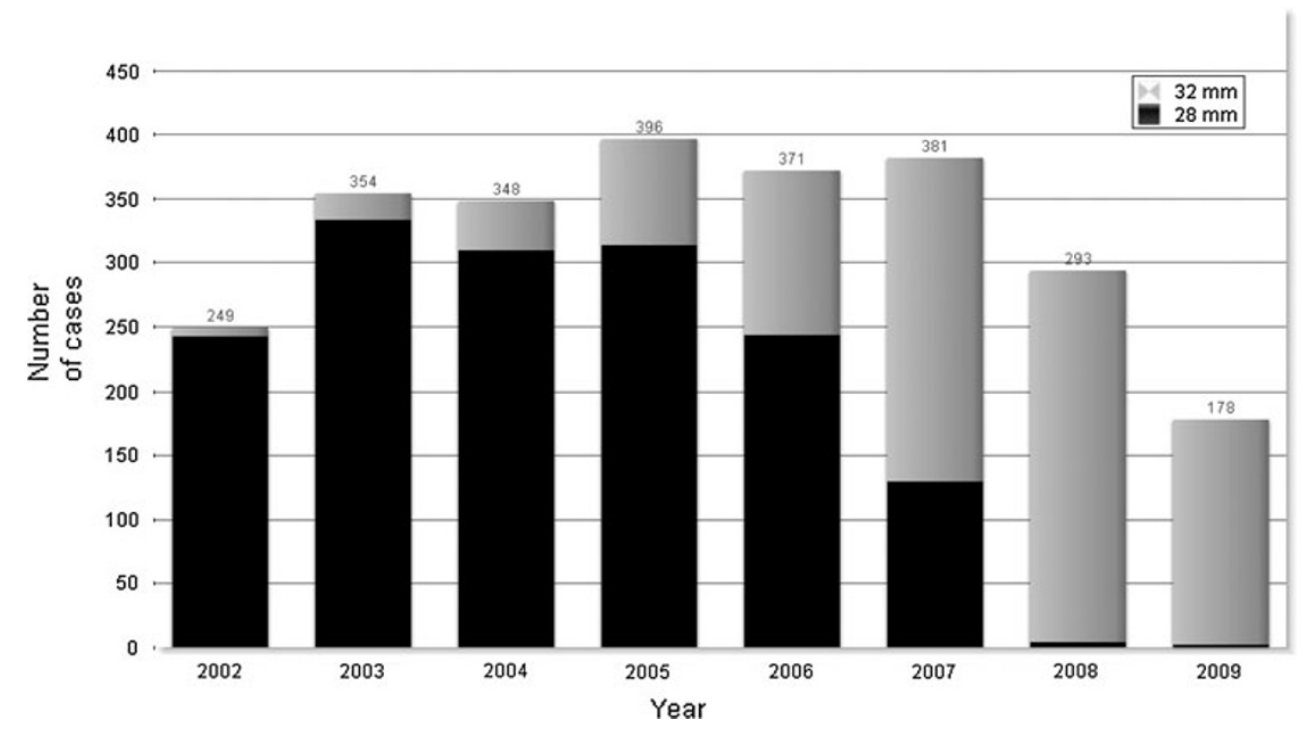


Table 1 Kaplan-Meier survival from dislocation for 28 and 32-mm femoral heads

\begin{tabular}{lll}
\hline Time (days) & \multicolumn{2}{l}{ Cumulative survival } \\
\cline { 2 - 3 } & $28-\mathrm{mm}$ head & 32-mm head \\
\hline 10 & $0.994(0.990-0.998)$ & $0.998(0.996-1.0)$ \\
50 & $0.986(0.980-0.992)$ & $0.997(0.993-1.0)$ \\
250 & $0.980(0.972-0.988)$ & $0.996(0.992-1.0)$ \\
500 & $0.976(0.968-0.984)$ & \\
1000 & $0.970(0.962-0.978)$ & \\
\hline
\end{tabular}

$(P=0.987)$, age $(P=0.272)$, diagnosis $(P=0.856)$, cup $(P=0.555)$, or stem $(P=0.523)$.

\section{Discussion}

In this study we evaluated the effect of femoral head diameter on the risk of dislocation. We found that the dislocation risk was significantly higher for the $28 \mathrm{~mm}$ diameter heads than for the $32 \mathrm{~mm}$ diameter heads, with a relative risk of 6 . In the whole cohort there were no significant associations with sex, age, diagnosis, or type of prosthesis.

The major weakness of our study is that it was not randomized. The strength of our study include a large study group of patients with strict inclusion criteria, all with diagnosis of osteoarthritis, undergoing surgery in the same hospital by the same surgeons, with the same surgical technique.

Most reports on femoral head diameters and dislocation have used historical controls, and only a few clinical studies have demonstrated that an increased femoral head diameter may reduce the risk of dislocation [7, 21-24], and most clinical studies have not demonstrated this effect [25-28]. One main reason for these discrepancies may be that in most cases hip dislocation has a multifactorial etiology, and the effect of a single variable requires a larger study population with control of operative and implant design variables. We isolated the effect of femoral head diameter as the single variable. Our study confirms and expands on previously published evidence that the dislocation rate is reduced by use of larger heads. Kelley et al. [21] found the rate of dislocation to be higher with a 22-mm-diameter head than with a $28-\mathrm{mm}$ head when a posterior operative approach was used. Hedlundh et al. [23] demonstrated a higher risk of recurrent dislocation, but not overall dislocation, for 2,875 hips treated with a Lubinus implant with a 32-mm head compared with 3,192 treated with a Charnley implant with a 22-mm head, but there was no difference in overall dislocation. Also Bystrom et al. [22] found that the rate of revisions because of dislocation was lower for 32-mm heads than for 28-mm heads. However, as only reoperation because of dislocation was used as the end point, and because many patients with a dislocation never have a reoperation, the relationship between head diameter and overall risk of dislocation could not be assessed by this study.

The literature suggests that more than half of all dislocations occur within the first three months after surgery and more than three quarters within one year [1], and one series demonstrated that $70 \%$ of dislocations after THA occurred within the first month after surgery [29]. Our observations are in agreement with these reports, because 37 of 53 dislocations occurred within 100 days after THA.
Fig. 2 Kaplan-Meier survival from dislocation for 28 and 32-mm femoral heads

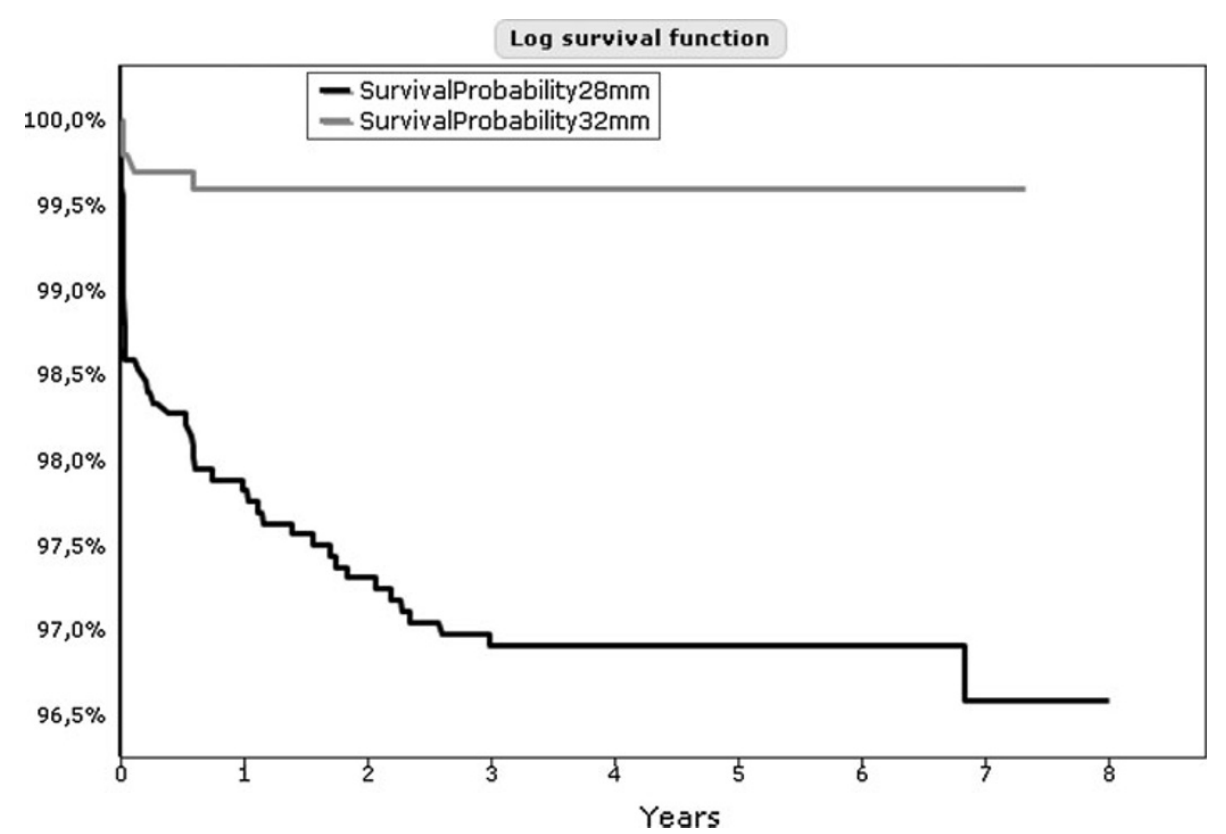


In a previous study multivariate analysis showed a moderate effect in favor of a 32-mm head compared with a 28-mm head [30]. The strongest effect was, however, the operative approach with a significantly higher risk of dislocation with the posterolateral approach than with the anterolateral and transtrochanteric approaches. Most series have reported that the dislocation rate after a posterior surgical approach to the hip is 2-3 times greater than that seen after an anterior approach [31-34]. At our clinic we have routinely used the posterolateral approach, and in the choice of changing operative or implant variable to reduce the risk of dislocation, we chose a larger femoral head because this was simpler. Also, the availability of bearing surfaces that have been predicted to have low wear rates even with larger head diameters led us to the use of $32 \mathrm{~mm}$ diameter femoral heads. This attitude was based on biomechanical and clinical studies that have suggested substantially reduced wear rates with XLPE compared with conventional polyethylene sterilized in an inert environment [14-17].

We could not find any difference in risk of dislocation between men and women. In one study dislocation was reported to occur 2.5 times as often in women as in men [1], but this was not verified in other studies [35-37]. Also it has been noted that patients' age is not a risk factor for dislocation [1, 36], but Ekelund et al. [38] found a nearly twofold risk of dislocation among very old patients (above 80 years). In our series, there were no associations between dislocation and sex and age.

In conclusion, our analyses of patients operated at our hospital indicate a significant association between femoral head diameter and rate of dislocation after THA. Otherwise we could not find any significant associations between dislocation and sex, age, diagnosis, or type of prosthesis.

\section{Conflict of interest None.}

Open Access This article is distributed under the terms of the Creative Commons Attribution Noncommercial License which permits any noncommercial use, distribution, and reproduction in any medium, provided the original author(s) and source are credited.

\section{References}

1. Woo RY, Morrey BF (1982) Dislocations after total hip arthroplasty. J Bone Joint Surg Am 64:1295-1306

2. Mahoney CR, Pellicci PM (2003) Complications in primary total hip arthroplasty: avoidance and management of dislocations. Instr Course Lect 52:247-255

3. Fender D, Harper WM, Gregg PJ (1999) Outcome of Charnley total hip replacement across a single health region in England: the results at five years from a regional hip register. J Bone Joint Surg Br 81:577-581

4. Forsythe ME, Whitehouse SL, Dick J, Crawford RW (2007) Functional outcomes after nonrecurrent dislocation of primary total hip arthroplasty. J Arthroplasty 22:227-230
5. Chandler RW, Dorr LD, Perry J (1982) The functional cost of dislocation following total hip arthroplasty. Clin Orthop Relat Res 168:168-172

6. Sanchez-Sotelo J, Berry DJ (2001) Epidemiology of instability after total hip replacement. Orthop Clin North Am 32:543-552 vii

7. Morrey BF (1992) Instability after total hip arthroplasty. Orthop Clin North Am 23:237-248

8. Scifert CF, Brown TD, Pedersen DR, Callaghan JJ (1998) A finite element analysis of factors influencing total hip dislocation. Clin Orthop Relat Res 355:152-162

9. Sultan PG, Tan V, Lai M, Garino JP (2002) Independent contribution of elevated-rim acetabular liner and femoral head size to the stability of total hip implants. J Arthroplasty 17:289-292

10. Livermore J, Ilstrup D, Morrey B (1990) Effect of femoral head size on wear of the polyethylene acetabular component. J Bone Joint Surg Am 72:518-528

11. Bragdon CR, Jasty M, Muratoglu OK, Harris WH (2005) Thirdbody wear testing of a highly cross-linked acetabular liner: the effect of large femoral head size in the presence of particulate poly(methyl-methacrylate) debris. J Arthroplasty 20:379-385

12. Hermida JC, Bergula A, Chen P, Colwell CW Jr, D'Lima DD (2003) Comparison of the wear rates of twenty-eight and thirtytwo-millimeter femoral heads on cross-linked polyethylene acetabular cups in a wear simulator. J Bone Joint Surg Am 85A:2325-2331

13. Muratoglu OK, Bragdon CR, O'Connor DO, Jasty M, Harris WH (2001) A novel method of cross-linking ultra-high-molecularweight polyethylene to improve wear, reduce oxidation, retain mechanical properties. Recipient of the 1999 HAP Paul Award. J Arthroplasty 16:149-160

14. Digas G, Karrholm J, Thanner J, Herberts P (2007) 5-year experience of highly cross-linked polyethylene in cemented and uncemented sockets: two randomized studies using radiostereometric analysis. Acta Orthop 78:746-754

15. Digas G, Karrholm J, Thanner J, Malchau H, Herberts P (2004) The Otto Aufranc Award. Highly cross-linked polyethylene in total hip arthroplasty: randomized evaluation of penetration rate in cemented and uncemented sockets using radiostereometric analysis. Clin Orthop Relat Res 429:6-16

16. Dorr LD, Wan Z, Shahrdar C, Sirianni L, Boutary M, Yun A (2005) Clinical performance of a Durasul highly cross-linked polyethylene acetabular liner for total hip arthroplasty at five years. J Bone Joint Surg Am 87:1816-1821

17. Engh CA Jr, Stepniewski AS, Ginn SD, Beykirch SE, SychterzTerefenko CJ, Hopper RH Jr, Engh CA (2006) A randomized prospective evaluation of outcomes after total hip arthroplasty using cross-linked marathon and non-cross-linked Enduron polyethylene liners. J Arthroplasty 21:17-25

18. Garcia-Rey E, Garcia-Cimbrelo E, Cruz-Pardos A, OrtegaChamarro J (2008) New polyethylenes in total hip replacement: a prospective, comparative clinical study of two types of liner. J Bone Joint Surg Br 90:149-153

19. Glyn-Jones S, McLardy-Smith P, Gill HS, Murray DW (2008) The creep and wear of highly cross-linked polyethylene: a threeyear randomised, controlled trial using radiostereometric analysis. J Bone Joint Surg Br 90:556-561

20. Triclot P, Grosjean G, El MF, Courpied JP, Hamadouche M (2007) A comparison of the penetration rate of two polyethylene acetabular liners of different levels of cross-linking. A prospective randomised trial. J Bone Joint Surg Br 89:1439-1445

21. Kelley SS, Lachiewicz PF, Hickman JM, Paterno SM (1998) Relationship of femoral head and acetabular size to the prevalence of dislocation. Clin Orthop Relat Res 355:163-170

22. Bystrom S, Espehaug B, Furnes O, Havelin LI (2003) Femoral head size is a risk factor for total hip luxation: a study of 42,987 
primary hip arthroplasties from the Norwegian Arthroplasty Register. Acta Orthop Scand 74:514-524

23. Hedlundh U, Ahnfelt L, Hybbinette CH, Wallinder L, Weckstrom J, Fredin H (1996) Dislocations and the femoral head size in primary total hip arthroplasty. Clin Orthop Relat Res 333:226-233

24. Alberton GM, High WA, Morrey BF (2002) Dislocation after revision total hip arthroplasty: an analysis of risk factors and treatment options. J Bone Joint Surg Am 84A:1788-1792

25. Dorr LD, Wolf AW, Chandler R, Conaty JP (1983) Classification and treatment of dislocations of total hip arthroplasty. Clin Orthop Relat Res 173:151-158

26. Fackler CD, Poss R (1980) Dislocation in total hip arthroplasties. Clin Orthop Relat Res 151:169-178

27. McCollum DE, Gray WJ (1990) Dislocation after total hip arthroplasty. Causes and prevention. Clin Orthop Relat Res 261:159-170

28. Ali Khan MA, Brakenbury PH, Reynolds IS (1981) Dislocation following total hip replacement. J Bone Joint Surg Br 63B:214-218

29. Williams JF, Gottesman MJ, Mallory TH (1982) Dislocation after total hip arthroplasty. Treatment with an above-knee hip spica cast. Clin Orthop Relat Res 171:53-58

30. Berry DJ, von KM, Schleck CD, Harmsen WS (2005) Effect of femoral head diameter and operative approach on risk of dislocation after primary total hip arthroplasty. J Bone Joint Surg Am $87: 2456-2463$
31. Horwitz BR, Rockowitz NL, Goll SR, Booth RE Jr, Balderston RA, Rothman RH, Cohn JC (1993) A prospective randomized comparison of two surgical approaches to total hip arthroplasty. Clin Orthop Relat Res 291:154-163

32. Roberts JM, Fu FH, McClain EJ, Ferguson AB Jr (1984) A comparison of the posterolateral and anterolateral approaches to total hip arthroplasty. Clin Orthop Relat Res 187:205-210

33. Robinson RP, Robinson HJ Jr, Salvati EA (1980) Comparison of the transtrochanteric and posterior approaches for total hip replacement. Clin Orthop Relat Res 147:143-147

34. Vicar AJ, Coleman CR (1984) A comparison of the anterolateral, transtrochanteric, and posterior surgical approaches in primary total hip arthroplasty. Clin Orthop Relat Res 188:152-159

35. Turner RS (1994) Postoperative total hip prosthetic femoral head dislocations. Incidence, etiologic factors, and management. Clin Orthop Relat Res 301:196-204

36. Paterno SA, Lachiewicz PF, Kelley SS (1997) The influence of patient-related factors and the position of the acetabular component on the rate of dislocation after total hip replacement. J Bone Joint Surg Am 79:1202-1210

37. Jolles BM, Zangger P, Leyvraz PF (2002) Factors predisposing to dislocation after primary total hip arthroplasty: a multivariate analysis. J Arthroplasty 17:282-288

38. Ekelund A, Rydell N, Nilsson OS (1992) Total hip arthroplasty in patients 80 years of age and older. Clin Orthop Relat Res 101-106 